\title{
Expression and Characterization of RNA-dependent RNA Polymerase of Dendrolimus punctatus Tetravirus
}

\author{
Liang Zhou, Jiamin Zhang, Xiaochun Wang, Hong Jiang, Fuming Yi and Yuanyang Hu* \\ State Key Laboratory of Virology, College of Life Sciences, Wuhan University, Wuhan, Hubei 430072, P R China
}

Received 19 February 2006, Accepted 19 May 2006

\begin{abstract}
Dendrolimus punctatus tetravirus (DpTV) has been identified as a new member of the genus Omegatetravirus of the family Tetraviridae that may be related serologically to Nudaurelia capensis virus $(\mathrm{N} \omega \mathrm{V})$. To establish the function of DpTV RNA genome and to better understand the mechanism of viral replication, the putative RNAdependent RNA polymerase (RdRp) domain has been cloned and expressed in Escherichia coli. The recombinant protein was purified on a Ni-chelating HisTrap affinity column and demonstrated to initiate viral RNA synthesis in a primer-independent manner but not by terminal nucleotidyle transferase activity in the presence of $\mathbf{M g}^{2+}$ and RNA template. Mutation of the GDD to GAA interferes with the residues at the polymerase active site and metal ions, and thus renders the polymerase inactive.
\end{abstract}

Keywords: Dendrolimus punctatus tetravirus, RNA-dependent RNA polymerase, RNA synthesis

\section{Introduction}

The family Tetraviridae comprises small RNA viruses whose host range is restricted to lepidopteran insects (butterflies and moths) (Hanzlik and Gordon, 1997). The Eighth edition of the ICTV taxonomy of viruses indicates a different status of tetravirus taxonomy (Fauquet et al., 2004). Viruses in this family have single-stranded, positive-sense RNA genomes encased in unenveloped, icosahedral virions that are 35 41 $\mathrm{nm}$ in diameter, with equilibrium densities in $\mathrm{CsCl}$ of $<1.30 \mathrm{~g}$ $\mathrm{cm}^{-3}$. The family now comprises 11 confirmed members, including two viruses whose complete nucleotide sequences have been reported and show different genomic organization, and eight unassigned possible members. The family Tetraviridae

\footnotetext{
*To whom correspondence should be addressed.

Tel: 86-27-68756654; Fax: 86-27-68754921

E-mail: yyhu@whu.edu.cn
}

is divided into the genera Betatetravirus and Omegatetravirus on the basis of capsid appearance and genome organization (Hendry et al., 1995; Hanzlik and Gordon, 1997; Pringle et al., 1999, 2003).

Betatetraviruses, such as Nudaurelia capensis $\beta$ virus $(\mathrm{N} \beta \mathrm{V})$, Thosea asigna virus $(\mathrm{TaV})$ and Providence virus $(\mathrm{PrV})$, have a monopartite genome with both the replicase and capsid precursor genes on an RNA molecule of $\sim 6.5 \mathrm{~kb}$. The capsid precursor gene is also present on a subgenomic RNA molecule of $\sim 2.5 \mathrm{~kb}$ (Gordon et al., 1999; Pringle et al., 1999, 2003). Omegatetraviruses, such as Nudaurelia capensis $\omega$ virus $(\mathrm{N} \omega \mathrm{V})$ and Helicoverpa armigera stunt virus (HaSV), have a bipartite genome with the replicase and capsid precursor genes on the $\sim 5.3$ and $\sim 2.5 \mathrm{~kb}$ RNA molecules, respectively (Agrawal and Johnson, 1992; Hanzlik et al., 1993, 1995; Gordon et al., 1995). Capsids of both genera contain two proteins: a major protein of $\sim 60 \mathrm{kDa}$ and a minor protein of $\sim 7 \mathrm{kDa}$.

Dendrolimus punctatus tetravirus (DpTV) has been identified as a new member of the genus Omegatetravirus of the family Tetraviridae that may be related serologically to Nudaurelia capensis $\omega$ virus $(\mathrm{N} \omega \mathrm{V})$. DpTV particles were isolated from diseased Dendrolimus punctatus, a member of the family Lasiocampidae, collected from Yunnan Province, China. Viral particles are isometric, with a diameter of about $40 \mathrm{~nm}$ and a buoyant density of $1.281 \mathrm{~g} \mathrm{~cm}^{-3}$ in $\mathrm{CsCl}$. The virus has two capsid proteins (of 62.5 and $6.8 \mathrm{kDa}$ ) and two single-stranded RNA molecules (RNA1 and RNA2), which are 5492 and 2490 nt long, respectively. RNA1 (Genbank, AY594352) has a large open reading frame (ORF) (nt 37-4986) encoding a polypeptide of $180 \mathrm{kDa}$; RNA2 (Genbank, AY594353) contains two partially overlapping ORFs encoding polypeptides of 17 and $70 \mathrm{kDa}$. The $180 \mathrm{kDa}$ protein, which contains consensus motifs of a putative methyltransferase, helicase and RNAdependent RNA polymerase, shows significant similarity to those of other tetraviruses (Yi et al., 2005).

To establish the functions of $180 \mathrm{kDa}$ protein and better understand the replication strategy, the RdRp domain predicted by sequence analysis (NCBI) has been cloned and expressed 
solublly in Escherichia coli as a recombinant protein. The three domains were named NS1 (methyltransferase), NS2 (helicase), NS3 (RNA-dependent RNA polymerase). Then the fusion protein was purified and demonstrated to have the ability to initiate RNA synthesis in a primer-independent manner. This work will be useful for the later study on the replication strategy of virus.

\section{Materials and Methods}

Virus purification and the extract of viral RNA. Frozen insect larve $(200 \mathrm{~g})$ were thawed and then were put into liquefacient nitrogen. The frozen particles were triturated with pestle and then homogenized in $500 \mathrm{ml}$ extration buffer $(0.05 \mathrm{M}$ Tris $/ \mathrm{HCl}, 1 \mathrm{mM}$ EDTA, pH 7.5, 0.2\% 2-mercaptoethanol). The homogenate was clarified by centrifugation at $10,000 \mathrm{~g}$ in a Biofuge Stratos rotor for $30 \mathrm{~min}$. The supernatant was precipitated by centrifuging at $100,000 \mathrm{~g}$ for $2 \mathrm{~h}$ in a Beckman Coulter Ti70 rotor. Virus pellets were resuspended overnight at $4^{\circ} \mathrm{C}$ in TE buffer $(0.05 \mathrm{M}$ Tris $/ \mathrm{HCl}$, $1 \mathrm{mM}$ EDTA, $\mathrm{pH}$ 7.5). The resuspended virus was centrifuged through a $30 \%(\mathrm{w} / \mathrm{v})$ sucrose cushion at $100,000 \mathrm{~g}$ for $3 \mathrm{~h}$. Virus pellets were resuspended again, then layered on a $10-40 \%(\mathrm{w} / \mathrm{v})$ sucrose gradient and centrifuged at $100,000 \mathrm{~g}$ for $2 \mathrm{~h}$ in a Beckman Coulter Ti40 rotor. The band containing virus particles was collected, diluted with TE buffer and pelleted at 100,000 $\mathrm{g}$ for $3 \mathrm{~h}$. Virus pellets were resuspended in $250 \mu \mathrm{TE}$ buffer and frozen for long-term storage. For further purification, virus in TE buffer was subjected to a $\mathrm{CsCl}$ density gradients according to Scotti (1985). The purity and integrity of the purified virus were verified by negative staining with $2 \%(\mathrm{w} / \mathrm{v})$ phosphotungstic acid (PTA, $\mathrm{pH} 7.0)$ and examined under a Hitachi H-8100 transmission electron microscope.

Viral RNA was extracted from capsids by using TRIzol reagent according to the manufacturer's instructions (Invitrogen).

cDNA synthesis and plasmid constructions. Open reading frames (ORFs) and RdRp domain (NS3) were identified by using BLAST (htttp://www.ncbi.nlm.nih.gov/BLAST/). The conserved sequences were aligned by using CLUSTAL_W version 1.8. With the result of sequence analysis, the former and reverse primers of NS3 were designed. cDNA fragments of NS3 complementary to DpTV RNA were synthesized in the presence of primier NS3Rev, dNTPs and ThermoScript reverse transcriptase (Invitrogen) as recommended by the manufacturer. Then the NS3 fragment was PCR amplified with the following primer pair-NS3For and NS3Rev-from cDNA. After purification, the PCR products were digested with $\mathrm{BamH}$ and Hind, and then inserted into the BamH/Hind sites of vector pET-28a (Novagen). The resulting expression vector, $p E T-$ NS3, which was driven by the T7 RNA polymerase promoter, was transformed into E. coli BL21 (DE3). Site-directed mutagenesis of GDD to GAA, containing the double substitution of both Asp1213 and Asp1214 to alanine, was carried out by overlapping PCR. The $\mathrm{N}$ terminal 835 bp fragment was amplified by NS3For and NS3m2, and the C terminal 269 bp fragment was amplified by NS3m1 and NS3Rev. Then the two fragments were purified and combined to generate the mutant NS3GAA using the outer primers NS3For and
NS3Rev. After digestion with BamH/Hind, the mutant fragment was subcloned into vector pET-28a. Transformants were analyzed by restriction enzyme mapping and confirmed by the dideoxy sequencing method.

Expression and purification of recombinant DpTV NS3. E. coli BL21 (DE3), transformed with either pET-NS3 or pET-NS3GAA, was grown in Luria-Bertani (LB) medium, at $37^{\circ} \mathrm{C}$, to an attenuance (D) at $600 \mathrm{~nm}$ of $\approx 1.0$. Then the temperature was lowed to $30^{\circ} \mathrm{C}$, and protein expression was induced for $4 \mathrm{~h}$ by the addition of $1 \mathrm{mM}$ isopropyl thio- $\beta$-D-galactoside (IPTG). The cell pellet obtained from $500 \mathrm{ml}$ of culture was resuspended in $20 \mathrm{ml}$ of binding buffer containing $50 \mathrm{mM}$ sodium phosphate, $\mathrm{pH} 8.0,500 \mathrm{mM} \mathrm{NaCl}$, $30 \mathrm{mM}$ imidazole, $10 \mathrm{mM} \beta$-mercaptoethanol, $10 \%$ glycerol, $1 \%$ Triton-X-100, $1 \mathrm{mM}$ phenylmethanesulfonyl fluoride, $10 \mu \mathrm{g} \mathrm{m}{ }^{-1}$ lysozyme. Then $20 \mu \mathrm{l}$ of DNase (Takara) was added to the suspension for $30 \mathrm{~min}$ on ice. The lysates were sonicated on ice to reduce viscosity, and any insoluble materials were removed by centrifugation at $13,000 \mathrm{~g}$ for $30 \mathrm{~min}$. The clear supernatant was applied to a $2 \mathrm{ml} \mathrm{Ni}$-chelating HisTrap affinity column (Novagen) preequilibrated with the binding buffer. The bound protein was then washed by binding buffer with $50 \mathrm{mM}$ imidazole and eluted with elution buffer ( $50 \mathrm{mM}$ sodium phosphate, $\mathrm{pH} 8.0,500 \mathrm{mM} \mathrm{NaCl}$, $5 \mathrm{mM} \beta$-mercaptoethanol, $10 \%$ glycerol) containing $300 \mathrm{mM}$ imidazole. The fractions were monitored by SDS-PAGE and staining with Coomassie Brilliant Blue R250, then, the His-tagged protein peaks were collected and dialyzed against buffer $(20 \mathrm{mM}$ Tris/ $\mathrm{HCl}, \mathrm{pH} 8.0,500 \mathrm{mM} \mathrm{NaCl}$ and $20 \%$ glycerol), followed by storage at $-80^{\circ} \mathrm{C}$ in small aliquots. The concentration of purified protein was determined by the Bradford method using BSA as a standard.

SDS/PAGE and western blot. Protein fractions from the HisTrap affinity column were separated by $12 \%$ SDS/PAGE and elecrotransferred to a PVDF membrane. The membrane was blocked with $3 \%$ BSA in TBS buffer $(\mathrm{pH} \mathrm{7.5)}$ and treated with rabbit anti-His. Alkaline phosphatase (ALP)-conjugated goat anti(rabbit IgG) was used as the secondary antibody. After washing three times with TBS buffer containing $0.1 \%$ Tween-20, membranebounded antibodies were detected with Nitro Blue tetrazolium/5bromo-4-chloroindol-2-yl phosphate.

Preparation of RNA template and RNA labeling. RNA templates were prepared by in vitro transcription using T7 Polymerase according to the manufacturer's instruction (Promega). The DNA fragments of $278 \mathrm{nt}(+)$ 5'-UTR of viral RNA2 were used as transcription templates. The products were further purified and blocked at the 3-hydroxyl group as described previously (Yi et al., 2003).

For preparation of digoxin (DIG)-labeled RNA probes complementary to the synthesized RNAs, the DNA fragments of (+) 5'-UTR of RNA2 were also used as templates for in vitro transcription. RNA labeling was performed according to the instruction manual supplied with DIG RNA labeling kit of Roche Molecule Biochemicals.

In vitro $\mathrm{RdRp}$ reaction. The in vitro $\mathrm{RdRp}$ standard assay was performed in a total volume of $50 \mu$ containing $20 \mathrm{mM}$ Tris/ $\mathrm{HCl}$, 
$\mathrm{pH} 8.0,5 \mathrm{mM} \mathrm{MgCl}, 5 \mathrm{mM} \mathrm{MnCl} 2,2 \mathrm{mM}$ dithiothreitol, $50 \mathrm{mM}$ $\mathrm{NaCl}, 0.25 \mathrm{mM}$ of each NTP, $0.4 \mu \mathrm{g}$ of RNA template and about $0.2 \mu \mathrm{g}$ of purified protein. The reaction mixtures were incubated at $25^{\circ} \mathrm{C}$ for $2 \mathrm{~h}$ and stopped by the addition of $20 \mathrm{mM}$ EDTA. The RNA products were extracted with acid phenol/chloroform $(1: 1$, $\mathrm{v} / \mathrm{v}$ ) followed by ethanol precipitation. Then the precipitates were dissolved with $20 \mu$ of diethyl pyrocarbonate-treated water.

Nothern bolt analysis. The precipitated RdRp products were dissolved in a denaturing buffer containing 95\% formamide, $10 \mathrm{mM}$ EDTA, $20 \mathrm{mM}$ Tris/ $\mathrm{HCl}, \mathrm{pH} 8.0$, at $100^{\circ} \mathrm{C}$ for $5 \mathrm{~min}$, and then separated by PAGE ( $8 \%$ gel containing $7 \mathrm{M}$ urea) in $1 \times$ Tris/ borate/EDTA (TBE) buffer. After electrophoresis, the gel was transferred to a positively charged nylon membrane (Hybond) and electroblotted for $4 \mathrm{~h}$ at $4^{\circ} \mathrm{C}$. The membrane was dried for $2 \mathrm{~h}$ at $80^{\circ} \mathrm{C}$ and exposed to ultraviolet irradiation $(254 \mathrm{~nm})$ for $2 \mathrm{~min}$ at $0.12 \mathrm{~J} \mathrm{sq} \mathrm{cm}^{-1}$. Hybridization was performed for $12 \mathrm{~h}$, at $68^{\circ} \mathrm{C}$, in $20 \mathrm{ml}$ of a solution containing $50 \%$ formamide, $2 \%$ blocking reagent (Roche), $5 \times \mathrm{SSC}$ and $20 \mathrm{~g} \mathrm{ml}^{-1}$ yeast tRNA, together with the DIG-labeled RNA transcripts. The excess probes were eliminated gradually by washing the membrane from low stringency $(1 \times \mathrm{SSC}$, $0.1 \% \mathrm{SDS})$ to high stringency $(0.2 \times \mathrm{SSC}, 0.1 \% \mathrm{SDS})$ at $68^{\circ} \mathrm{C}$. Then, the bound RNA was treated with ALP-conjugated anti-DIG Ig $(1: 5000)$ in dilution buffer $(1 \times$ blocking reagent in $0.1 \mathrm{M}$ maleic acid buffer, $\mathrm{pH} 7.5$ ) for $30 \mathrm{~min}$. The reaction complexes were visualized using CSPD, according to the manufaturer of DIG RNA detection kit (Roche).

RT-PCR detection. The strand-specific oligodeoxynucleotide primers, 5'-UTRfor, complementary to the synthesized minus-strand RNAs, were used for RT-catalyzed cDNA synthesis, followed by PCR amplification of cDNA. Ten microlitres of dissolved RNA were subjected RT with Thermoscript ${ }^{\mathrm{TM}} \mathrm{RT}$ according to the manufacturer's instructions (Invitrogen). PCR was performed with 5'-UTRfor and 5'-UTRrev primers for detection of synthesized minus-strand RNA.

\section{Results}

Virus purification and cDNA synthesis. When negatively stained with PTA, the viral particles appeared isometric and non-enveloped, had a mean diameter of $40 \mathrm{~nm}$, same to the previous report of DpTV (Yi et al., 2005) (Fig. 1).

The PCR product of cDNA appeared about $1080 \mathrm{bp}$ in $0.7 \%$ agrose electrophoresis, matching with the respective length. Later restriction enzyme mapping and sequencing confirmed this fragment was the target.

Sequence analysis. NS3 was located on the large ORF, encoding a polypeptide from Lys940 to Asp1299, 360 residues long (Fig. 2). NS3 contained all eight conserved motifs that were identified by Poch et al. (1989), Candresse et al. (1990), and Koonin et al. (1993) as common to the RNAdependent RNA polymerase of replicases of positive-stranded RNA viruses (Fig. 3). The three motifs IV, V and VI showed completely unequivocal conservation. They were located at aa 1123-1128 (DX 4 D), 1181-1190 (SGXTXN) and 1212-1214

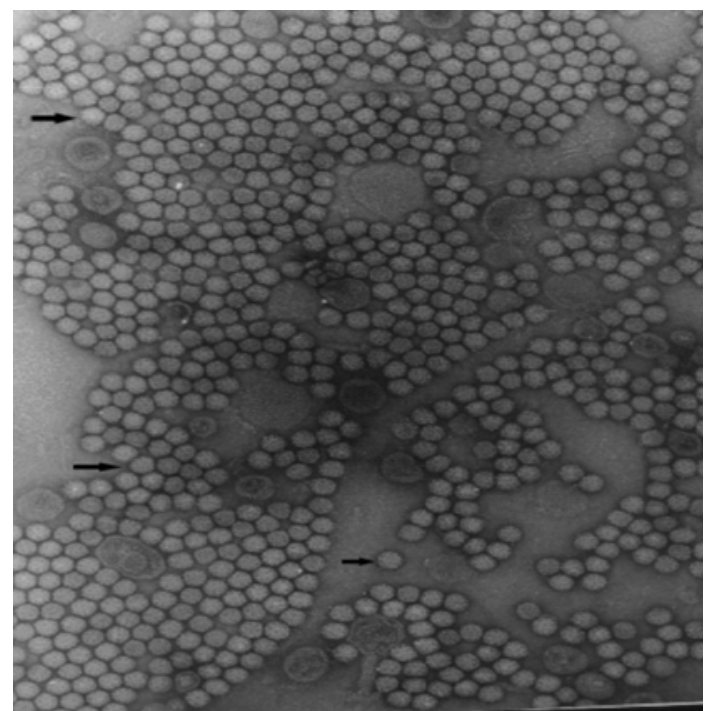

Fig. 1. Transmission electron micrograph of negative-stained virions. Black arrows indicate virions.

(GDD). The conserved GDD motif was located in the active center of HIV-1 revers transcriptase (Kohlstaedt et al., 1992). Inokuchi et al. (1987) assumed that this motif is concerned with the course of metal ion combining with catalysis site of enzyme, which had been proved in the RNA polymerase of poliovirus (Jablonski et al., 1993). Mutation of the motif could cause enzyme inactivation. The sequence of the RNAdependent RNA polymerase domain of DpTV shared 76\% identity with that of $\mathrm{HaSV}$ and $36 \%$ with that of NV.

Expression and purification of the recombinant RdRp proteins. Two vectors including pET-NS3 and pET-NS3GAA expression plasmids were examined to obtain the soluble recombinant protein about $42 \mathrm{kDa}$ from $E$. coli transformants. The protein was identified as the recombinant NS3 by Western blot analysis using rabbit anti-His as primary antibody (Fig. 3), since the recombinant NS3 has a His-tag at the N-terminal. The other mutant protein, NS3GAA, was expressed and purified in paralled to the NS3 protein.

RNA synthesis activity of the recombinant NS3 protein. The activities of the fusion protein (NS3 and NS3GAA) were tested using 5'-end of plus-strand RNA2 transcripts. The RNA products synthesized by NS3 protein were detected using a Nothern blot assay and RT-PCR. The activity of NS3 protein has been shown to be primer-independent (Fig. 4). The predominant RNA products migrated similarly to the respective RNA template (278 nt for synthesized plus-strand RNA) (Fig. 5). The mutated NS3 protein, NS3GAA, in which the GDD sequence was substituted to GAA did not exhibit any $\operatorname{RdRp}$ activity in the presence of templates. This result shows that the RNA synthesis activity of the NS3 protein absolutely requires the presence of the GDD motif. 


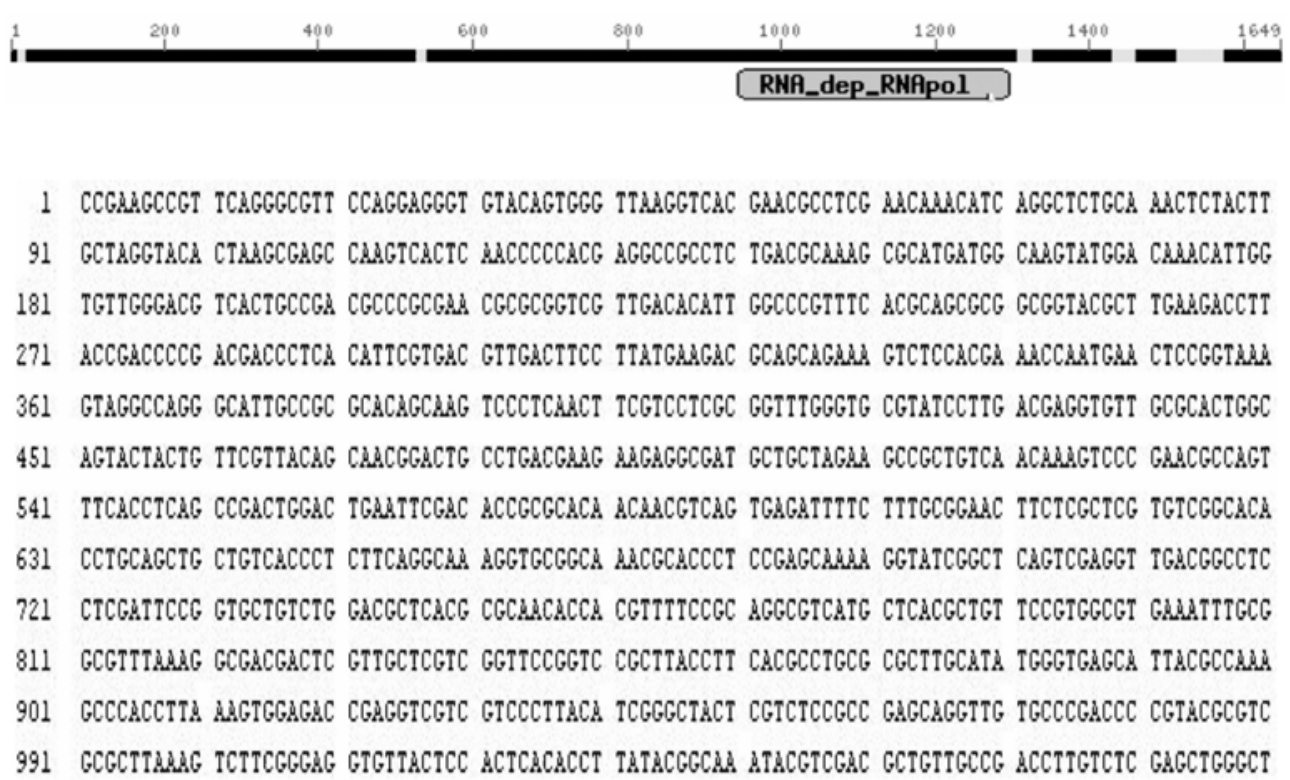

Fig. 2. NS3 (RdRp domain) location on the $180 \mathrm{kDa}$ polyprotein and its DNA sequence. (A) NS3 (RdRp domain) location on the $180 \mathrm{kDa}$ polyprotein. The large ORF on the RNA1 is $4950 \mathrm{nt}$ long, which encodes a $180 \mathrm{kDa}$ polyprotein carrying 1650 residues. NS3 encodes a polypeptide from Lys940 to Asp1299, 360 residues long. (B) DNA sequence of NS3 (RdRp domain). The sequence on the RNA1 (Genbank, AY594352) is between nt 2849 and nt 3928.

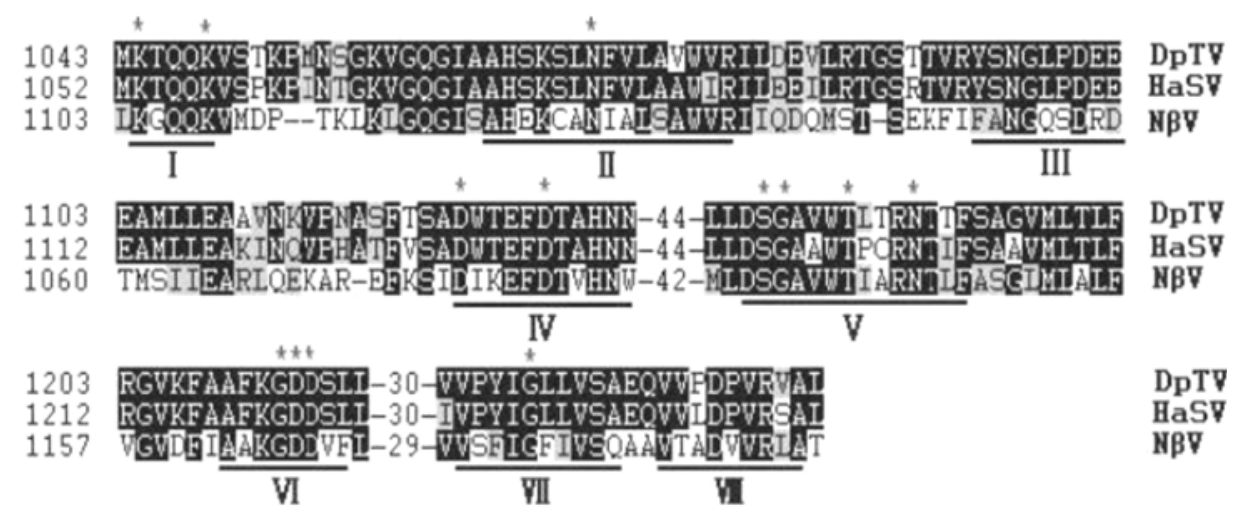

Fig. 3. Comparison of amino acid sequence of DpTV RdRp protein with conserved motifs from HaSV and NV. Roman numerals indicate conserved motifs designated by Koonin et al. (1992). Asterisks indicate amino acid residues within these motifs that are highly conserved among a range of virus families in the alpha-like superfamily (Koonin et al., 1992; Gordon et al., 1995). Numbers on the left indicate the starting amino acid positions of the aligned sequences. Residues identical in at least two of the viruses are shown on a black background.

\section{Discussion}

To isolate the functional NS3 protein from other viral and cellular proteins and to establish an in vitro replication system for studying viral RNA replication, NS3 protein with His-tag was expressed in an E. coli system. Earlier attempts to express and purify the soluble protein had been hampered as a result of the poor solubility. When the temperature of induction was lowed to $30^{\circ} \mathrm{C}$, the solubility of protein was improved significantly.

Previously, there were some reports that the enzymatic activity of fusion protein with a hexahistidine tag at the N- terminus lost (Plotch et al., 1989; Hobson et al., 2001; Kashiwagi et al., 2002). However, the recombinant NS3 protein was functionally active. No RNA products were obtained in the absence of purified NS3 protein or RNA templates and in the presence of NS3GAA protein and RNA template, indicating that purified NS3 protein was not contaminated with T7 RNA polymerase or RNA/DNA that could serve as a template as previous reporter (Triana-Alonso et al., 1995). Furthermore, mutation of the conserved motif, GDD, to GAA almost abolished RNA synthesis, similar to the reports for HCV RdRp (Ranjith-Kumar et al., 2001; Wang et al., 2002) and CSFV RdRp (Yi et al., 2003). These results 


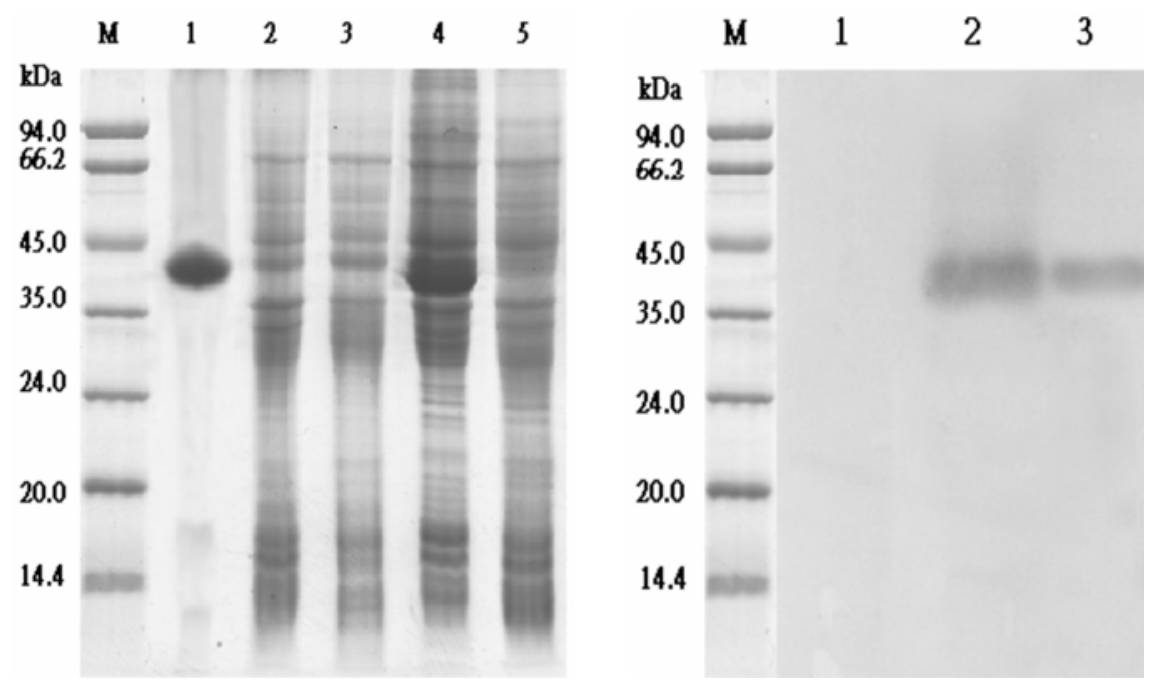

Fig. 4. Expression and purification of DpTV NS3 and NS3GAA fusion proteins from Escherichia coli. (A) Proteins were expressed and purified as described in the materials and methods. Fractions of sample eluted from the HisTrap affinity column by imidazole were separated by SDS/PAGE (12\% gel) and stained with Coomassie Brilliant Blue. Lane M, molecular mass markers; Lane 1, purified fusion protein; Lane 2, lysate precipitation of induced BL21 (DE3) expressing fusion proteins; Lane 3, lysate supernatant of induced BL21 (DE3) expressing fusion proteins; Lane 4, induced BL21 (DE3) expressing fusion proteins; Lane 5, pET-28a vector as a control. (B) Western blot analysis of the purified proteins. Lane 1, pET-28a vector as a negative control; Lane 2, NS3 protein; Lane 3, NS3GAA protein.

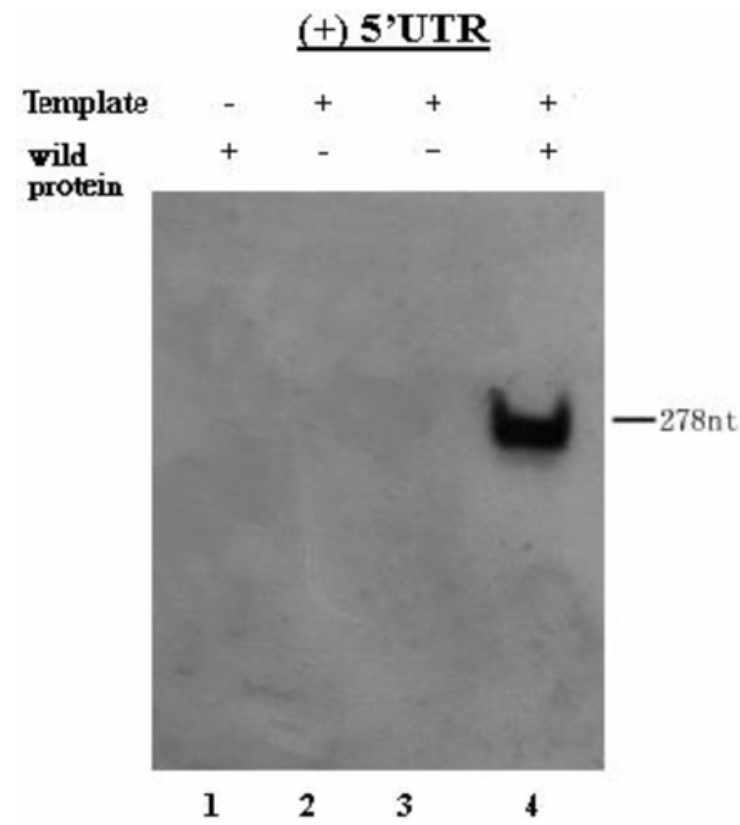

Fig. 5. RNA-dependent RNA polymerase (RdRp) activity of DpTV NS3 protein. The RNA template was purified before use. RNA products were separated by PAGE (8\% gel containing $7 \mathrm{M}$ urea) and detected by Nothern blot. 5-UTR RNA was used as template. Lane 1, absence of RNA template; Lane 2, absence of NS3 protein; Lane 3, presence of NS3GAA protein and RNA template; Lane 4, presence of NS3 protein and RNA template.

showed that purified NS3 fusion protein possessed RdRp activity in vitro.

Because DpTV is a novel virus, functional analysis of viral

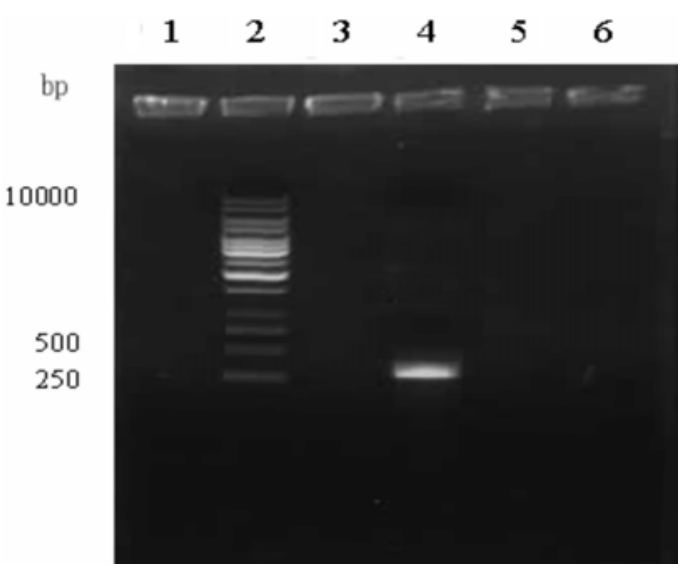

Fig. 6. Detection of in vitro synthesized negative-strand RNA by RT-PCR. Lane 1, no protein in the reaction system; Lane 2, $1 \mathrm{~kb}$ DNA ladder; Lane 3, both the RNA template and NS3GAA in the reaction system; Lane 4, both the RNA template and NS3 in the reaction system; Lane 5, no RNA template in the reaction system; Lane 6, only NS3GAA protein in the reaction system.

genome can reveal information regarding the key event in virus life cycle. The $180 \mathrm{kDa}$ protein may play a key role in the replication of virus. The replicases of at least five tetraviruses have been sequenced and a theoretical analysis of the replicases of some of these viruses has been published a few years ago (Gorbalenya et al., 2002). Its three distinct functional domains are common to replication proteins of all members of the alpha-like superfamily. These domains are usually translated as a polyprotein and are, in order from the amino terminus, a possible methyltransferase domain, the 
Table 1. Primers used in this study

\begin{tabular}{cl}
\hline Primers & \multicolumn{1}{c}{ Sequence $\left(5^{\prime}-3^{\prime}\right)$} \\
\hline NS3For & TTTCGCGGATCCCCGAAGCCGTTCAGGG \\
NS3Rev & TTTGGGTTCGAATTAAGCCCAGCTCGAGACAAG \\
NS3m1 & CGTTTAAAGGCGCCGCCTCGTTGC \\
NS3m2 & GCAACGAGGCGGCGCCTTTAAACG \\
5'-UTRfor & AACATCTGCGACGACAAAAC \\
5'-UTRrev & GAGCCGTCTATGAAGGCGAG \\
\hline
\end{tabular}

nucleotide-binding or helicase domain, and the polymerase domain characterized by the GDD box (Goldbach et al., 1991; Koonin et al., 1992). Evidence concerning their functions is accumulating. The postulated methyltransferase domain covers the stretch of sequence which in Sindbis virus contains amino acid residues implicated in methyltransferase activity and mRNA capping (Mi et al., 1989; Cong and Shuman, 1995). Mutagenesis studies of the conserved nucleotidebinding domain of the vaccinia virus helicase (Gross and Shuman, 1995), in addition to biochemical studies on the predicted helicase of the rubella virus (Gros and Wengler, 1996) and of the poliovirus GDD or polymerase domain (Jablonsk and Morrow, 1993; Walker et al., 1995), support roles for these domains in viral RNA replication.

The ss+RNA viruses in the alpha-like superfamily use a considerable variety of strategies for the expression of their replication proteins. The alphavirus replicase includes additional domains and is processed during the replication cycle (Strauss and Strauss, 1994); the HEV replicase also includes additional domains and is probably processed to yield functional proteins (Reyes et al., 1990; Koonin et al., 1992). Two other plant virus groups in the alpha-like superfamily (the potexviruses and tymoviruses) are known to express all three domains as a single protein comparable in length to those of $\mathrm{HaSV}$ and HEV (Goldbach et al., 1991). However, the concensus sequence of the amino-terminal domains of the replicases of these viruses differs from that of the tetraviruses and comparable viruses (Candresse et al., 1990). The threedomain tymovirus replication protein has been shown to undergo posttranslational cleavage (Morch et al., 1989).

Other viruses in this superfamily use read-through of stop condons to express the three-domain replication proteins. These include the tobamoviruses and tobraviruses, whose most abundant proteins carry only the first two domains, with the polymerase domain lying downstream from the stop codon. In another strategy, the tripartite viruses (AIMV and $\mathrm{BMV}$ ) produce distinct polypeptides carrying either the first two domains or the third alone: specific regions in each of the BMV proteins are involved in assembly of functional complexes involving multiple subunits (Kao and Ahlquist, 1992).

DpTV replicase lacks the other domains identified in the replicase polyprotein of vertebrate viruses like HEV and the alphaviruses, i.e., the papain-like protease and the proline-rich hinge domains implicated in autoprocessing of the replicase polyproteins. The $180 \mathrm{kDa}$ protein is therefore unlikely to be self-processed into smaller functional proteins, as seems to generally be the case for the vertebrate RNA viruses, and may therefore funtion as a single molecule, like some plant RNA viruse replicases. However the possibility of trans processing has not been excluded, the active expression of RdRp domain of DpTV replicase in vitro suggests this way. Experimental elucidation of the proteins expressed during viral replication in insect cells is required to determine whether the replicase protein is processed. However, a major hindrance to the study of tetraviruses has been the lack of a cell culture system (Moore and Tinsley, 1982). Therefore, many functions of viral genome have to be confirmed in vitro.

Acknowledgments This work was supported by the National Natural Science Foundation of China (no. 30170037).

\section{References}

Agrawal, D. K. and Johnson, J. E. (1992) Sequence and analysis of the capsid protein of Nudaurelia capensis virus, an insect virus with $\mathrm{T}=4$ icosahedral symmetry. Virology 190, 806-814.

Candresse, T., Morch, M. D. and Dunez, J. (1990) Multiple alignment and hierarchical clustering of conserved amino acid sequences in the replication-associated proteins of plant RNA viruses. Res. Virol. 141, 315-329.

Cong, P. J. and Shuman, S. (1995) Mutational analysis of mRNA capping enzyme identifies amino acids involved in GTP binding, enzyme-guanylate formation, and GMP transfer to RNA. Mol. Cell. Biol. 15, 6222-6231.

Fauquet, C. M., Mayo, M. A., Maniloff, J., Desselberger, U. and Ball, L. A. (2004) Virus Taxonomy: Eighth Report of the International Committee on Taxonomy of Viruses. pp. 1258, Elsevier/Academic Press, London, UK.

Goldbach, R. W., Le Gall, O. and Wellink, J. (1991) Alpha-like viruses in plants. Semin. Virol. 2, 19-25.

Gorbalenya, A. E., Pringle, F. M., Zeddam, J. L., Luke, B. T., Cameron, C. E., Kalmakoff, J. K, Hanzlik, T. N., Gordon, K. H. and Ward, V. K. (2002) The palm subdomain-based active site is internally permuted in viral RNA-dependent RNA polymerases of an ancient lineage. J. Mol. Biol. 324, 47-62.

Gros, C. and Wengler, G. (1996) Identification of an RNAstimulated NTPase in the predicted helicase sequence of the Rubella virus nonstructural polyprotein. Virology 217, 367-372.

Gross, C. H. and Shuman, S. (1995) Mutational analysis of vaccinia virus nucleoside triphosphate phosphohydrolase II, a DExH box RNA helicase. J. Virol. 69, 4727-4736. 
Gordon, K. H. J., Johnson, K. N. and Hanzlik, T. N. (1995) The larger genomic RNA of Helicoverpa armigera stunt tetravirus encodes the viral RNA polymerase and has a novel 3-terminal tRNA-like structure. Virology 208, 84-98.

Gordon, K. H. J., Williams, M. R., Hendry, D. A. and Hanzlik, T. N. (1999) Sequence of the genomic RNA of Nudaurelia virus (Tetraviridae) defines a novel virus genome organization. Virology 258, 42-53.

Hanzlik, T. N. and Gordon, K. H. J. (1997) The Tetraviridae. Adv. Virus. Res. 48, 101-168.

Hanzlik, T. N., Dorrian, S. J., Gordon, K. H. J. and Christian, P. D. (1993) A novel small RNA virus isolated from the cotton bollworm, Helicoverpa armigera. J. Gen. Virol. 74, 1805-1810.

Hanzlik, T. N., Dorrian, S. J., Johnson, K. N., Brooks, E. M. and Gordon, K. H. J. (1995) Sequence of RNA2 of the Helicoverpa armigera stunt tetravirus (Tetraviridae) and bacterial expression of its genes. J. Gen. Virol. 76, 799-811.

Hendry, D. A., Johnson, J. E., Rueckert, R. R., Scotti, P. D. and Hanzlik, T. N. (1995) Family Tetraviridae. In virus Taxonomy: Sixth Report of the International Committee on Taxonomy of Viruses, Murphy, F. A., Fauquet, C. M., Bishop, D. H. L., Ghabrial, S. A., Jarvis, A. W., Martelli, G. P., Mayo, M. A. and Summers, M. D., (eds.), pp. 372-375, Springer, New york, USA.

Hobson, S. D., Rosenblum, E. S., Richards, O. C., Richmond, K., Kirkegaard, K. and Schultz, S. C. (2001) Oligomeric structures of poliovirus polymerase are important for function. EMBO. J. 20, 1153-1163.

Inokuchi, K. and Hirashima, A. (1988) Interference with viral infection by defective RNA replicase. J. Virol. 61, 3946-3949.

Jablonski, S. A. and Morrow, C. D. (1993) Enzymatic activity of poliovirus RNA polymerases with mutations at the tyrosine residue of the conserved YGDD motif: isolation and characterization of polioviruses containing RNA polymerases with FGDD and MGDD sequences. J. Virol. 67, 373-381.

Kao, C. C. and Ahlquist, P. (1992) Identification of the domains required for direct interaction of the helicase-like and polymerase-like RNA replication proteins of brome mosaic virus. J.Virol. 66, 7293-7302.

Kashiwagi, T., Hara, K., Kohara, M., Kohara, K., Iwahashi, J., Hamada, N., Yoshino, H. and Toyoda, T. (2002) Kinetic analysis of C-terminally truncated RNA-dependent RNA polymerase of hepatitis $\mathrm{C}$ virus. Biochem. Biophys. Res. Commun. 290, 1188-1194.

Kohlstaedt, L. A., Wang, J. and Friedman, J. M. (1992) Crystal structure at 3.5 A resolution of HIV-1 revers transcriptase complexes with an inhibitor. Science 256, 1783-1790.

Koonin, E. V. and Dolja, V. V. (1993) Evolution and taxonomy of positive-strand RNA viruses: implications of comparative analysis of amino acid sequences. Crit. Rev. Biochem. Mol. Biol. 28, 375-430.

Koonin, E. V., Gorbalenya, A. E., Purdy, M. A., Rozanov, M. N., Reyes, G. R. and Bradley, D. W. (1992) Computer-assisted assignment of functional domains in the nonstructural polyprotein of hepatitis $\mathrm{E}$ virus: delineation of an additional group of positive-strand RNA plant and animal viruses. Proc. Natl. Acad. Sci. USA 89, 8259-8263.

Mi, S., Durbin, R., Huang, H. V., Rice, C. M. and Stollar, V. (1989) Association of the Sindbis virus RNA methyltransferase activity with the nonstructural protein nsP1. Virology 170, 385391.

Moore, N. F. and Tinsley, T. W. (1982) The small rna-viruses of insects. Arch. Virol. 72, 229-245.

Morch, M. D., Drugeon, G., Szafranski, P. and Haenni, A. L. (1989) Proteolytic origin of the 150-kilodalton protein encoded by turnip yellow mosaic virus genomic RNA. J. Virol. 63, 5153-5158

Plotch, S. J., Palant, O. and Gluzman, Y. (1989) Purification and properties of poliovirus RNA polymerase expressed in Escherichia coli. J. Virol. 63, 216-225.

Poch, O., Sauvaget, I., Delarue, M. and Tordo, N. (1989) Identification of four conserved motifs among the RNAdependent polymerase encoding elements. EMBO. J. 8, 38673874.

Pringle, F. M., Gordon, K. H. J., Hanzlik, T. N., Kalmakoff, J., Scotti, P. D. and Ward, V. K. (1999) A novel capsid expression strategy for Thosea asigna virus (Tetraviridae). J. Gen. Virol. 80, 1855-1863.

Pringle, F. M., Johnson, K. N., Goodman, C. L., Mclntosh, A. H. and Ball, L. A. (2003) Providence virus: a new member of the Tetraviridae that infects cultured insect cells. Virology 306, 359-370.

Ranjith-Kumar, C. T., Gajewski, J., Gutshall, L., Maley, D., Sarisky, R. T. and Kao, C. C. (2001) Terminal nucleotidyl transferase activity of recombinant Flaviviridae RNAdependent RNA polymerases: implication for viral RNA synthesis. J. Virol. 75, 8615-8623.

Reyes, G. R., Purdy, M. A., Kim, J. P., Luk, K. C., Young, L., Fry, K. E. and Bradley, D. W. (1990) Isolation of a cDNA from the virus responsible for enterically transmitted non-A, non-B hepatitis. Science 247, 1335-1339.

Scotti, P. D. (1985) The estimation of virus density in isopycnic cesium chloride gradients. J. Virol. Methods 12, 149-160.

Strauss, J. H. and Strauss, E. G. (1994) The alphaviruses: gene expression, replication, and evolution. Microbiol. Rev. 58, 491562.

Triana-Alonso, F. J., Dabrowski, M., Wadzack, J. and Nierhaus, K. H. (1995) Self-coded 3-extension of runoff transcripts produces aberrant products during in vitro transcription with T7 RNA polymerase. J. Biol. Chem. 270, 6298-6307.

Walker, D. E., McPherson, D., Jablonski, S. A., McPherson, S. and Morrow, C. D. (1995) An aspartic acid at amino acid 108 is required to rescue infectious virus after transfection of a poliovirus cDNA containing a CGDD but not SGDD amino acid motif in 3Dpol. J. Virol. 69, 8173-8177.

Wang, C., Sarnow, P. and Siddiqui, A. (1994) A conserved helical element is essential for internal initiation of translation of hepatitis C virus RNA. J. Virol. 68, 7301-7307.

Yi, F. M., Zhang, J. M., Yu, H. Y., Liu, C. F., Wang, J. P. and Hu, Y. Y. (2005) Isolation and identification of a new tetravirus from Dendrolimus Punctatus larvae collected from Yunnan Province, China. J. Gen. Virol. 86, 789-796.

Yi, G. H., Zhang, C. Y., Cao, S., Wu, H. X. and Wang, Y. (2003) De novo RNA synthesis by a recombinant classical swine fever virus RNA-dependent RNA polymerase. Eur. J. Biochem. 270, 4952-4961. 